\title{
Sex differences in hypokalaemic and electrocardiographic effects of inhaled terbutaline
}

\author{
Abdul R A Rahman, Denis G McDevitt, Allan D Struthers, Brian J Lipworth
}

\begin{abstract}
Background Gender differences in the chronotropic effects of infused isoprenaline have previously been described. The aim of the present study was to investigate possible gender differences in hypokalaemic, chronotropic, and electrocardiographic effects of inhaled terbutaline.
\end{abstract}

Methods Twenty healthy volunteers (10 female) were recruited (mean age 24 years for women (F) and 22 years for men (M). Subjects were given either inhaled terbutaline $5 \mathrm{mg}$ or placebo in single blind, randomised crossover fashion and the following measurements were made for four hours after inhalation: $(a)$ serum potassium concentration; (b) heart rate; (c) electrocardiographic sequelae ( $T$ wave amplitude, $Q$-Tc interval). The effects of terbutaline on serum potassium was chosen as the primary end point for detecting a $0.3 \mathrm{mmol} / 1$ difference between sexes, with a $\beta$ error of 0.2 and $\alpha$ set at 0.05 . Results The hypokalaemic effects of terbutaline were significantly greater in women, the potassium results (means and $95 \% \mathrm{CI})$ being as follows: lowest potassium concentration-F $3 \cdot 12 \quad(2 \cdot 96-3 \cdot 28)$ mmol/1 $v$ M 3.65 (3.49-3.81) mmol/1; percentage change from baseline at one hour-F $15 \cdot 4 \%(11 \cdot 5-19 \cdot 3 \%)$ v M 8.5\% $(4 \cdot 6-12 \cdot 3 \%)$; average potassium concentration during the four hours-F 3.39 (3.33-3.46) mmol/1 $v M$ 3.78 (3.72-3.85) mmol/1. There was no significant regression between body weight and the potassium response to terbutaline. There were also significant sex differences for $T$ wave, $Q-T c$, and heart rate response. The percentage fall in $\mathrm{T}$ wave amplitude $30 \mathrm{~min}$ utes after terbutaline was: F 44.6\% (32.1$57 \cdot 0 \%$ ) $v$ M $22 \cdot 4 \%(9 \cdot 9-34 \cdot 8 \%)$.

Conclusions Women are more sensitive to the hypokalaemic, chronotropic, and electrocardiographic sequelae of inhaled terbutaline.

(Thorax 1992;47:1056-1059)

Stimulation of $\beta_{2}$ adrenoceptors causes intracellular influx of potassium into skeletal muscle, which is mediated via a membrane linked $\mathrm{Na}^{+} / \mathrm{K}^{+}$adenosine triphosphatase pump. ${ }^{12}$ The hypokalaemia induced by inhaled $\beta_{2}$ agonists occurs in a dose dependent fashion and is associated with electrocardiographic (ECG) changes, including $T$ wave blunting, $U$ waves, S-T depression, and prolongation of the Q-Tc interval. ${ }^{3}$ Whether hypokalaemia and arrhythmias induced by $\beta_{2}$ agonists are relevant to deaths from asthma is debatable, ${ }^{4-6}$ though the extracellular potassium ion concentration is an important determinant of myocardial membrane potential..$^{7-9}$ Hypokalaemia is, however, known to be a major risk factor for arrhythmogenesis in patients with underlying ischaemic heart disease. ${ }^{1011}$ One study suggested that women may be more sensitive to the chronotropic effects of infused isoprenaline. ${ }^{12}$ In the light of recent concerns about the safety of inhaled $\beta_{2}$ agonists, ${ }^{13}$ we designed a study to investigate possible gender differences in hypokalaemic and electrocardiographic effects of inhaled $\beta_{2}$ agonists.

\section{Methods}

SUBJECTS

Twenty healthy volunteers (10 female) were recruited. The men's mean (SE) age was 24 $(1.2)$ years and body weight $75 \cdot 2(2.4) \mathrm{kg}$ and the women's $21.6(0.5)$ years and $59.3(2.0) \mathrm{kg}$. All subjects had normal results in physical, biochemical, and electrocardiographic screening tests. Four men and three women were smokers, and four women were taking oral oestrogen contraceptive pills.

\section{STUDY DESIGN}

Subjects were studied at 1400 hours on two occasions separated by one week, and were given either inhaled terbutaline $5 \mathrm{mg}$ or identical placebo in a single blind, randomised, crossover design. Subjects were asked to refrain from alcohol, cigarettes, and drinks containing caffeine for 24 hours before each visit. They lay supine for the duration of the study period. Two baseline measurements were made 10 minutes apart once the heart rate had settled during an initial 30 minute resting period. Measurements were then repeated 30 minutes after inhalation of terbutaline $5 \mathrm{mg}$ or placebo. The terbutaline was administered as five actuations (specially prepared $1 \mathrm{mg}$ per actuation) separated by one minute intervals, and delivered by a pear shaped spacer device (Nebuhaler) to avoid individual differences in inhaler technique.

\section{MEASUREMENTS}

Measurements included serum potassium concentration and $T$ wave amplitude and $Q-T$ interval (from ECG strips of at least five complexes). Blood samples were separated in a 
Figure 1 A-Mean (SE) percentage change from baseline in serum potassium concentration over four hours after inhalation of terbutaline $5 \mathrm{mg}$ in men (filled boxes) and women (open boxes). The percentage change was significantly greater in women up to two hours after inhalation $\left({ }^{\star} p<0.01\right)$

$B-$ Individual responses showing serum potassium concentrations at baseline before inhalation of terbutaline (closed circles) and the maximal response after terbutaline (open circles) in men and women.
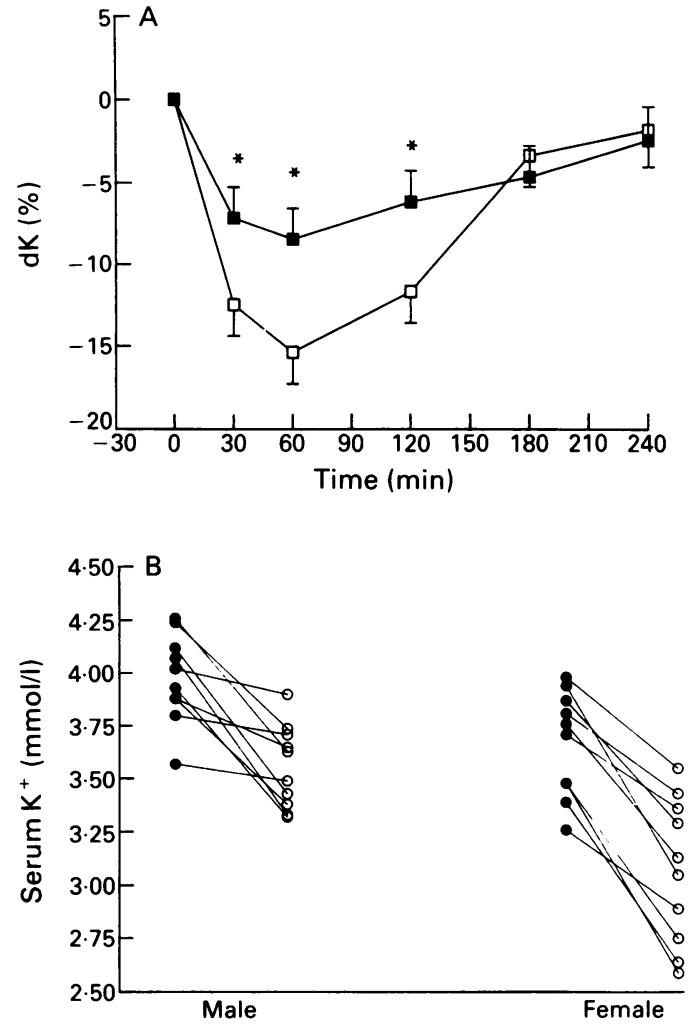

centrifuge within 10 minutes of collection and immediately stored.

Serum potassium was measured by flame photometry (IL 943 analyser, Instrumentation Laboratory, Warrington) in batches after completion of the study. The within and between assay values for analytical imprecision (expressed as coefficients of variation, $\mathrm{CV}$ ) were $0.7 \%$ and $1 \cdot 8 \%$. The normal reference range for our laboratory is $3.5-5.0 \mathrm{mmol} / \mathrm{l}$. All ECG measurements were obtained from the mean of five complexes from standard lead II, with a paper speed of $50 \mathrm{~mm} / \mathrm{s}$ and a gain of 0.5 $\mathrm{mv} / \mathrm{cm}$. Heart rate was assessed from the $R-R$ interval. The heart rate corrected $Q-T$ interval (Q-Tc) was calculated from the Bazett formula. ${ }^{14}$

\section{STATISTICAL ANALYSIS}

The study was designed to detect a $0.3 \mathrm{mmol} / 1$ difference in potassium response between sexes with a power of at least $80 \%$ (that is, $\beta=0 \cdot 2$ ) and $\alpha$ set at $0 \cdot 05$. Data were analysed by using a Statgraphics software package (STSC Software Publishing Group, Rockville, Maryland, USA). Multifactorial analysis of variance was used, with sex, subjects, time, and treatments used as within factors for the analysis. Regression analysis (by analysis of variance) was performed by the least squares method. We considered $\mathrm{p}$ values below 0.05 (two tailed) as significant. Potassium concentrations were averaged over the four hours. This is effectively equivalent to calculating the area under the curve (AUC) as this is calculated as average concentration $\times$ time (time being a constant). Data are presented as means and $95 \%$ confidence intervals.

\section{Results}

POTASSIUM

There were no significant gender differences in baseline potassium concentrations on the placebo day, although the concentration tended to be slightly lower in women: F 3.73 (3.603.86) $\mathrm{mmol} / 1$ v M 3.83 (3.70-3.96) $\mathrm{mmol} / 1$. Serum potassium did not significantly change after inhalation of placebo in either sex.

Baseline potassium was lower in women before they inhaled terbutaline: F 3.69 (3.53$3.85) \mathrm{mmol} / \mathrm{l} v \mathrm{M} 3.99(3.83-4.16) \mathrm{mmol} / \mathrm{l}$ (p < $0.05)$. Terbutaline inhalation caused a significant fall in serum potassium in both sexes $(p<0.0001)$. For both sexes the lowest potassium concentration occurred one hour after inhalation, with a significant gender difference: F 3.12 (2.96-3.28) mmol/1 v M 3.65 (3.49-3.81) $\mathrm{mmol} / \mathrm{l}(\mathrm{p}<0.001)$. The percentage fall in serum potassium from baseline at one hour was also greater in women: F $15.4 \%(11.5-19.3 \%)$ v M 8.5\% (4.6-12.3\%) (p<0.01); fig 1A). There were no gender differences in potassium responses three hours after terbutaline inhalation.

The average potassium concentrations throughout the four hours after terbutaline were significantly lower in women: F 3.39 (3.33-3.46) $\mathrm{mmol} / \mathrm{l}$ v $\mathrm{M} 3.78$ (3.72-3.85) $\mathrm{mmol} / 1(\mathrm{p}<0.0001)$. In terms of individual concentrations of potassium, four out of the 10 women fell below $3.0 \mathrm{mmol} / \mathrm{l}$ but none of the men. The lowest recorded potassium concentration was $2.58 \mathrm{mmol} / \mathrm{l}$ (fig 1B). Regression
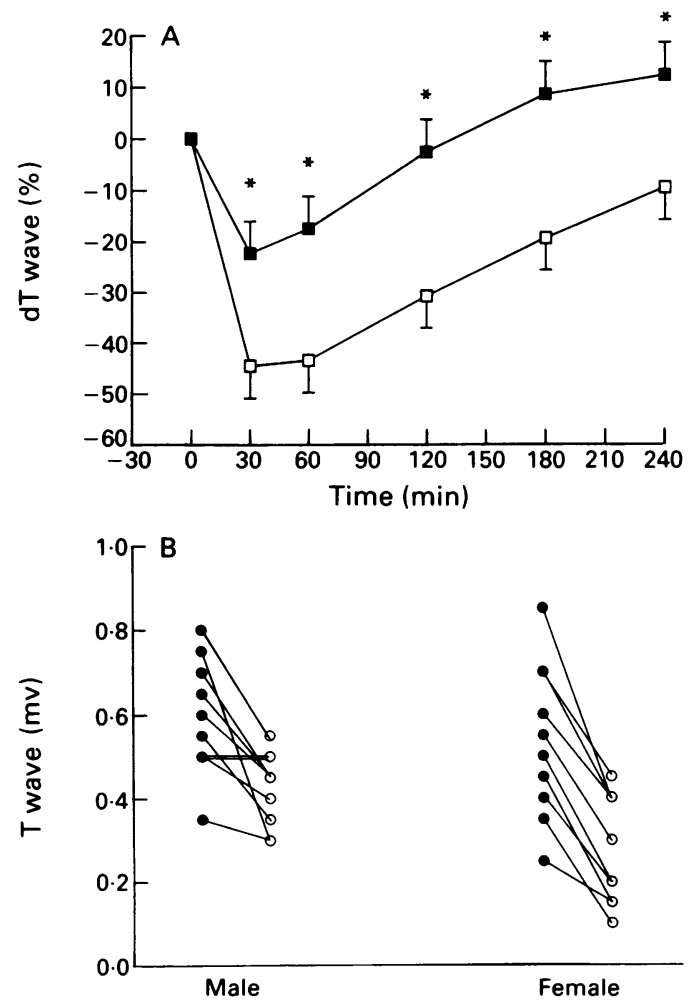

Figure 2 A-Mean ( $S E$ ) percentage change from baseline in $T$ wave amplitude over a four hour period after inhalation of terbutaline $5 \mathrm{mg}$ in men (filled boxes) and women (open boxes). The percentage change was significantly greater in women throughout the four hours of monitoring $\left({ }^{\star} p<0.01\right)$. B-Individual responses showing $T$ wave amplitude at baseline before inhalation of terbutaline (closed circles) and the maximal response after terbutaline (open circles) in men and women. 
analysis showed no significant correlation $(r=-0 \cdot 22)$ between body weight and maximal individual responses to terbutaline.

\section{ELECTROCARDIOGRAPHIC CHANGES}

Baseline $T$ wave amplitude was not significantly different between the sexes for the two study days: placebo-F $0.53(0.42-0.63) \mathrm{mV} v \mathrm{M}$ $0.62(0.52-0.72) \mathrm{mV}$ : terbutaline-F 0.54 $(0.45-0.62) \mathrm{mV} v \mathrm{M} 0.59(0.50-0.68) \mathrm{mV}$. T wave amplitude was not significantly altered in either sex after inhalation of placebo. Terbutaline significantly attenuated $T$ wave amplitude in both sexes $(p<0.0001)$. The fall in amplitude was maximal at 30 minutes and was lower in women: F $0.30(0.21-0.39) \mathrm{mV} v$ M $0.45(0.36-0.53) \mathrm{mV}(\mathrm{p}<0.05)$. The percentage fall in $\mathrm{T}$ wave amplitude at 30 minutes was $\mathrm{F} 44.6 \%(32 \cdot 1-57 \cdot 0 \%) v \mathrm{M}$ $22.4 \%(9.9-34.8 \%)(\mathrm{p}<0.01)$; (fig $2 \mathrm{~A})$. T wave amplitude returned to baseline two hours after inhalation in the men whereas in the women $\mathrm{T}$ wave amplitude remained significantly blunted even at the end of the four hours $(p<0.01)$. The maximal fall in $T$ wave amplitude was also greater in women (fig 2B). There was no significant regression $(r=-0 \cdot 23)$ between body weight and maximal individual response to terbutaline.

Six women showed ST depression after terbutaline compared with only one man. Five women also developed $U$ waves after terbutaline compared with only one man. Terbutaline caused prolongation of Q-Tc, which was greater in the women. Average $\mathrm{Q}-\mathrm{Tc}$ values were: F 424 (417-432) ms v M 403 (395-410) ms $(p<0.001)$. The $Q-T c$ interval remained significantly $(p<0.001)$ prolonged in the women for four hours after terbutaline but had returned to baseline by the same time in the men.

\section{CHRONOTROPIC RESPONSE}

The baseline heart rate was lower in women on both study days. There was no sex difference in the peak absolute heart rate achieved after they had inhaled terbutaline. This occurred $30 \mathrm{~min}-$ utes after inhalation: F $79(72-86)$ beats/min $v$ M 78 (71-86) beats $/ \mathrm{min}$. The duration of response was, however, significantly greater in women: the heart rate after four hours was F 73 (65-80) beats/min $v \mathrm{M} 61$ (54-69) beats $/ \mathrm{min}$ (p $<0.05$ ). Women showed a significantly greater peak increase in response to terbutaline: $F 25$ (16-34) beats/min $v \mathrm{M} 14$ (7-21) beats/min (p $<0.01)$. There was no correlation $(\mathrm{r}=-0.32)$ between body weight and response to terbutaline.

\section{Discussion}

This study was designed to investigate whether women showed greater sensitivity than men to the systemic adverse effects of inhaled terbutaline. Our data showed a clear sex difference in the hypokalaemic, chronotropic, and ECG responses to terbutaline. Both the nadir potassium concentration and the average potassium concentration over four hours were lower in women. The average potassium concentration over four hours represents the total hypokalaemic burden over this period and is probably the most clinically relevant variable in this respect. The maximal effect of terbutaline on ECG changes and potassium concentrations showed temporal correlation between the sexes, whereas recovery to normal of these variables did not. Both $T$ wave and $Q-T c$ changes remained significantly different after four hours but potassium concentrations did not show any difference between the sexes after three hours, when data were expressed as percentage change from baseline.

What are the possible explanations of the gender differences in extrapulmonary $\beta_{2}$ adrenoceptor responsiveness? Firstly, weight could conceivably have played a part. Our female volunteers were lighter in weight and therefore received a higher dose per unit body weight. We found no correlation, however, between absolute change in potassium concentration and body weight. This is supported by a previous study, ${ }^{12}$ which showed that the greater chronotropic response to infused isoprenaline was also independent of body weight. Unfortunately, the plasma concentration of terbutaline was not measured and so we are unable to determine whether the greater pharmacodynamic response in women was due to a difference in the pharmacokinetics of the inhaled drug between the sexes. Conceivably the effects of body weight might assume greater importance during chronic dosing, once steady state concentrations have been achieved.

The hormone differences and particularly the presence of female steroid hormones might also play a part. We did not study our female volunteers at the same phase of their menstrual cycle and could not therefore eliminate this particular possibility. The oral contraceptive pill taken by some of the women could also explain the sex difference but, as with body weight, there was no pattern in the individual responses to suggest this. Equal numbers of women and men smoked and smoking could not therefore account for the difference in response. A more likely explanation is that the differences might be due to the effect of sex hormones on $\beta_{2}$ adrenoceptors. This could be due to differences either in $\beta_{2}$ receptor density or affinity or in $G$ protein coupling to adenylate cyclase. Studies now in progress are investigating this hypothesis by comparing lymphocyte $\beta_{2}$ adrenoreceptors and in vivo $\beta_{2}$ responses at different phases of the menstrual cycle.

We may also speculate about the cause of Q-Tc prolongation and its possible arrhythmogenic potential with respect to $\beta_{2}$ agonists. Inhaled salbutamol and isoprenaline cause similar dose-response effects on Q-Tc and heart rate at equivalent doses by weight $(500-4000$ $\mu \mathrm{g})$, though inhaled isoprenaline causes only minimal hypokalaemia, which implies that falls in extracellular potassium are not responsible for the Q-Tc effect. ${ }^{15}$ As inhaled $\beta_{2}$ agonists have negligible effects on serum magnesium, this suggests that Q-Tc prolongation may be due to direct sympathomimetic effects rather than to extracellular electrolyte changes. It is also known that $\mathrm{Q}-\mathrm{Tc}$ prolongation may predispose 
to the development of torsades de pointes arrhythmia. ${ }^{16}$ The latter, however, is usually associated with bradycardia and is commonly treated by rapid pacing, and so the tachycardia response to $\beta_{2}$ agonists would if anything tend to protect against this phenomenon.

The clinical relevance of sex differences in extrapulmonary $\beta_{2}$ responsiveness remains only speculative at present. They do, however, suggest that women are more susceptible to systemic adverse effects of inhaled $\beta_{2}$ agonists. Excess mortality in young men has, however, been observed in an epidemiological study. ${ }^{17}$ Mortality in asthma is multifactorical and hypokalaemia may contribute but is clearly not the cause of the excess mortality in younger men. Other epidemiological studies, however, do not show any gender difference in asthma mortality. ${ }^{1819}$ Nevertheless, asthma control is known to deteriorate during the premenstrual period, and differences in receptor sensitivity may help to explain this. ${ }^{20}$ The clinician should be alerted to the possibility of greater hypokalaemic, chronotropic, and electrocardiographic effects in women receiving $\beta_{2}$ agonists.

We wish to thank Mrs J Thomson for typing the manuscript and Mrs L McFarlane for performing, the potassium assays.

1 Struthers AD, Reid JL, Whitesmith R, Rodger JC. The effects of cardioselective and non-selective $\beta$-adrenoceptor blockade on the hypokalaemic and audiovascular responses to adrenomedullary hormones in man. Clin Sci 1983; 63:143-7.

2 Lipworth BJ, McFarlane LC, Coutie WJ, McDevitt DG. Evaluation of the metabolic responses to inhaled salbutamol in the measurement of beta-2 adrenoceptor blockade. Eur J Clin Pharmacol 1989;37:297-300.

3 Lipworth BJ, McDevitt DG, Struthers AD. Systemic $\beta$ adrenoceptor responses to salbutamol given by metereddose inhaler alone and with pear shaped spacer attachment: comparison of electrocardiographic, hypokalaemic and haemodynamic effects. Br J Clin Pharmacol 1989;27: 837-42.

4 Sears MR, Rea HJ, Fenwick J, Gillies AJD, Holst PE,
O'Donnell TV, et al. Seventy five deaths in asthmatics prescribed home nebulisers. $B M J$ 1987;294:477-80.

5 Higgins RM, Cookson WOCM, Lane DJ, John SM, McCarthy GL, McCarthy ST. Cardiac arrhythmias caused by nebulised beta-agonist therapy [letter]. Lancet 1987;ii:863-4.

6 Ebden P, Farrow PR, Shaw D, Cookson JB. Seventy five deaths in asthmatics prescribed home nebuliser [letter]. deaths in asthmatic

7 Surawicz B, Lepeschin E, Herrlich HC, Hoffman BF. Effect of potassium and calcium deficiency on the monophasic action potential, electrocardiogram and contractility of isolated rabbit hearts. Am J Physiol 1959;196:1303-7.

8 Bennet P, McKinney L, Begenisich T, Kass R. Adrenergic modulation of the delayed rectifer potassium channel in calf cardiac purkinje fibres. Biophys $J$ 1986;49:839-49.

9 Roden DM, Iansmith DHS. Effects of low potassium or magnesium concentrations on isolated cardiac muscle. $\mathbf{A m}$ $J$ Med 1987;82(suppl 3A): 18-23.

10 Stewart DE, Ikram H, Espiner EA, Nicholls MG. Arrhythmogenic potential of diuretic induced hypokalaemia in patients with mild hypertension and ischaemic heart disease. Br Heart J 1985;54:290-7.

11 Nordrehaug JE, Johannessen KE, Von Der Lippe G. Serum potassium concentration as a risk factor of ventricular arrhythmias early in acute myocardial infarction. Circulation 1985;71:645-9.

12 Johansson SR, Hjalmarson AKE. Age and sex differences in cardiovascular reactivity to adrenergic agonists, mental stress and isometric exercise in normal subjects. Scand $J$ Clin Lab Invest 1988;48:183-91.

13 Lipworth BJ, McDevitt DG. Inhaled $\beta_{2}$-adrenoceptor agonists in asthma: help or hindrance? Br J Clin Pharmacol 1992;33:129-38.

14 Bazett HC. An analysis of the time relations of electrocardiograms. Heart 1920;7:353-70.

15 Lipworth BJ, Tregaskis BF, McDevitt DG. Comparison of hypokalaemic electrocardiographic and haemodynamic responses to inhaled isoprenaline and salbutamol in young and elderly subjects. Eur J Clin Pharmacol 1991;40: 255-60.

16 Surawicz B, Knoebel S. Long QT: good bad or indifferent? J Am Coll Cardiol 1985;4:494-516.

17 Burney PGJ. Asthma mortality in England and Wales: evidence for a further increase, 1974-84. Lancet 1986;ii: 323-6.

18 Crane J, Pearce N, Flatt A, Burgess C, Jackson R, Kwong T, et $a l$. Prescribed fenoterol and death from asthma in New Zealand, 1981-1983: case-control study. Lancet 1989;i: 917-22.

19 Grainger J, Woodman K, Pearce N, Crane J, Burgess C, Keane $A$, et al. Prescribed fenoterol and death from asthma in New Zealand, 1981-7: a further case-control study. Thorax 1991;46:105-11.

20 Pauli BD, Reid RL, Munt PW, Wigle RD, Forkert L. Influence of the menstrual cycle on airway function in asthmatic and normal subjects. Am Rev Respir Dis 1989; 140:358-62. 